\title{
ETHICS AND FETAL MEDICINE
}

\author{
Makoto Higurashi, ${ }^{1}$ Kumiko IIJima, ${ }^{1}$ Hideoki FuKuoKa, ${ }^{1}$ \\ and Yutaka NAKAHORI ${ }^{2}$ \\ ${ }^{1}$ Department of Maternal and Child Health and ${ }^{2}$ Department of Human Genetics, \\ The University of Tokyo, School of Health Sciences, \\ Bunkyo-ku, Tokyo 113, Japan
}

\begin{abstract}
Summary Ethical issues in the clinical practice of fetal medicine are discussed, largely from the point of view of early prenatal medicine. The discussion concentrates on several aspects including the time when human life begins, the pros and cons of fetal medicine, and ethical guidelines for fetal medicine. The emphasis is placed on the importance of informed consent and an increase in genetical knowledge amongst the general public.
\end{abstract} Key Words ethics, fetal medicine, guideline

\section{INTRODUCTION}

Progress in molecular biology has brought the tremendous scientific advances in all fields of medicine. Advanced medical technology has come to be able to handle the life easily. However, new scientific knowledge and resultant technologies create complex ethical dilemmas for society. Society has a critical stake in both successfully treating genetic disorders and maintaining respect for the human dignity of the fetus. Consequently society is rather anxious about what is going on in molecular genetics. The availability of gene-therapy and therapy for a defective fetus will cause more questions to be raised in the public conscience about who the fetus is.

According to the Oxford English Dictionary the usage of the word "ethics" has taken on a broad connotation over the years. While in its strict sense it means the science of morals, it has come to encompass "the science of human duty in its widest extent, including, besides ethics proper, the science of law, whether civil, political or international." It may also be used to describe practices which are acceptable to particular groups such as the medical or legal professions. Now, we are not equipped to deal with the moral problems raised by the practice of clinical genetics. However, as we learn more about developmental genetics and become increasingly adept at transferring genes from cell to cell, we may be tempted

Received March 19, 1993; Revised version accepted July 20, 1993. 
to move into areas of research which involve early fetal tissue or living human embryos. Here we may encounter particularly difficult ethical problems. So we believe there is a need for ethical consensus in medical genetics today, because the future in the discipline will be ethically more complex than that of the past. Ethical guidelines on fetal medicine should be openly discussed by the scientists, clinicians, nursing staffs, theologians, philosophers, and the general public.

\section{1.thical decisions in medicine, especially in fetal medicine}

There have been ethical guidelines in medicine since the time of Hippocrates, 24 or 25 centuries ago. The Hippocratic oath seems to have been one of practical philosophy, which aims to realize good at the level of the individual. Recently, another ethical problem, that is raised by remarkably advance in biology, in particular, the ability to manipulate human DNA, has arisen and ethical decisions in medicine have come to have two aspects. The first, described in Hippocratic oath, can be called "ethics for clinical medicine," and the second, newly born as a consequence of advances in molecular biology, can be called "ethics in experimental medicine." A clinical doctor finds difficulty in his choice, when he vacillates to apply a new medical technology for his patient (including fetus). Although they appear to be two distinct ethics to us at a glance, it is very important for one medical doctor to adjust in his heart, especially for a clinical doctor.

Why are ethical issues on fetal medicine seriously discussed? We think fetal medicine is the clinical medicine which the focuses on human reproduction and the initial development of a human being, and it is intimately related with the birth of a live being. This is the reason why fetal medicine has the ethical specificity. Why should the fetus be discussed apart from children?

There are four reasons (Shinagawa, 1987): (1) a fetus is very small and weak, (2) the fetus unlike adults cannot give informed consent, (3) medical intervention on the fetus may have harmful effects, (4) fetal medicine involves entering the "sacred space," which results in psychological pressure on medical staffs. On thinking about fetal medicine with such kinds of ethical speciality, we encounter with the difficulty to be able to decide the normative guideline, from the Sanctity of life-view. The major challenge for human genetics in the next decade will be to try to understand how genes are regulated during development. Therefore, it is possible to visualize a time when we may wish to apply the tools of the new genetics to study early fetal tissue or living embryos; then we may run into more serious ethical problems.

\section{When does human life begin?}

Already, our new found ability to tinker with genes or to diagnose fetal birthdefects has achieved considerable sophistication. However, new scientific knowledge and resultant technologies create complex ethical dilemmas for society. Soc- 
iety has a critical stake both in the successful treatment of fetal diagnoses or fetal birth-defects and in the maintenance of respect for the human dignity of the fetus.

It was over a decade ago when the first test-tube baby, Louise Brown, was born to be artificially fertilized by Steptoe and Edwards (1978). Following this event, guide-lines on embryo research were hotly debated. The question of whether or not we should experiment on embryos or use them, or tissue or cells from them, for therapeutic or research purpose is one that will not go away. The United Kingdom Government set up a Committee to address the whole business of embryo research.

The availability of therapy for a defective fetus will cause more question to be raised in the public conscience about who the fetus is. This complex problem may be considered from the point of vicw of the beginning of human life, present attitudes towards early fetal life, some moral considerations, and so on. Each field, embryology, obstetrics, law, and theology, has a different opinion about the beginning of human life. It is at the time of implantation in obstetrics and criminal law, it is at birth in civil law. There is another opinion that the fertilization is the beginning of human life. However, some disagree with this opinion; although the product of fertilization, the zygote, is a new form, it is still not a new individual either by scientific or by general standards.

When someone takes the position that the fertilization is beginning of human life, the experimenting on embryo should not always be allowed. So he tried to find a room for compromise between the necessity of embryo research and the ethical propriety.

Life begins when the chemical matter gives rise, in a specific way, to an autonomous, self-regulating and self-reproducing system. Life is connected with a living being, and it creates its own system as an indivisible whole. That is to say, it has individuality (Kurjak and Beazley, 1985). A living being demonstrates variability, individual development, and harmony. It is exactly this individuality that constitutes one of the most essential characteristics of the human being. It includes bodily features, special behavior and the capability to recognize and adapt. These characteristics gradually develop into human fetuses. It may be found harmony between the necessity of research and bioethical propriety that the establishment of individuality is the beginning of human life.

Many persons have discussed this critical point such as when an embryo attains the status of a human being with individuality, and, in particular, at what stage of development it is capable of appreciating external stimulation.

The Warnock Committee, the expert committee set up by the British Government under the Chairmanship of Mary Warnock, come to the conclusion that the human embryo should be protected. Because the members of the Committee believed that the embryo might have potential for sensory perception after 14 days, they suggested that research on human embryos after this stage of development should be made illegal. Rev. Norman has suggested it is 16 days after fertilization 
when the primitive streak appears. Singer, a philosopher, has suggested a later stage of gestation, up to 6 weeks (Singer, 1990). The ethics Committee of the American Fertility Society termed the embryo before 14 days post fertilization as "preembryo," The guidelines of Japanese Society of Obstetrics and Gynecology agree with the opinion of the Warnock Committee (The Warnock Committee, 1984).

\section{Pros and Cons of fetal medicine}

Techniques involved in prenatal diagnosis or fetal therapy include amniocentesis, chorionic villus sampling, tapping of fetal blood, fetal blood transfusion, pharmacological or biochemical treatments, operative therapies for lower urogenital obstruction or diaphragmatic hernia, etc. Although, technologies are widely used, they have been criticized. On the other hand, there are a lot of difficulties involved up in establishing of fetal therapy.

Thus opinions on fetal therapy are split. The importance of research on fetuses/embryos closely related to fetal medicine, are advocated by individuals of various social standings. However, others have taken a stand against prenatal diagnosis and fetal therapy, because many burden of pregnant women and fetuses may be supposed and induced abortions of abnormal fetus may increase.

So let us examine the pros and cons of fetal/embryonal research? The positive comments to fetal research are:

(1) To prevent the occurrence of congenital defects and spontaneous abortion and to treat fetuses in utero, it is necessary to conduct fetus research.

(2) It is impossible to inspect and to treat the fetus without using fetal tissues or cells.

(3) Fetal/embryonal research is necessary in itself, because so much about fetal development remains unknown.

(4) There is a question to oppose the fetal/embryonal research, while they approve of lots of induced abortions.

The negative comments on fetal/embryonal research are:

(1) Such research may create a casual attitude toward human life.

(2) Fundamental fetal rights should be respected.

(3) Such research may increase the number of induced abortions.

(4) (This issue is referred to experimentation on embryos) It is wrong to destroy an entity which has the potential to become a person (Marshall, 1990).

The fourth point, just made, is the minority view of the Warnock Committee; experiments on embryos should not be allowed, not because that life begins at the moment of fertilization, but because this entity clearly has the potential to become a person. Prof. J. Marshall, a member who supported the minority view of the Warnock Committee, said that in opposing experimentation he recognized and did not hide the fact that some advances in knowledge would be lost, but he felt that these advances were not so great as the scientists would have us believe. 


\section{A normative guideline for ethics of fetal medicine}

During the last few years remarkable advances in molecular biology have led to the development of methods for isolating and determining the fine structure of genes and for studying their function in the test tube. As these techniques have been refined and simplified, they have been applied to the study of human genes.

Furthermore, as we learn more about developmental genetics and become increasingly adept at transferring genes from cell to cell, we may be tempted to move into areas of research which involve early fetal tissue or living human embryos. Here we may encounter particularly difficult ethical problems.

For handling the fetus on embryo, we wish to propose the following as the proper attitude of researchers from the ethical point of view:

(1) An ethical limitation should be established such that the techniques used in fetal medicine are limited to the diagnosis and treatment of genetic diseases.

(2) The vital importance of an ethical brake should not be overestimated. It was severely encountered by the forum of public opinion that artificial fertilization or in vitro fertilization was once applied to humankind. At first in vitro fertilization was only applied to cases of sterilization. However, the criticism was suppressed and this method has come to be used as therapy for infertility as time goes by, we wonder that the ethical brake may be lifted and the indications for this method may be expanded, as the results.

(3) It is a very important ethical issue for the medical doctor to give clients medical information. We must recognize that in general, people's suspicions of specialists, including medical doctors, run very deep. People feel uneasy what may be done in the medical actions. On giving information, it is essential to explain to the clients in comprehensible words. It can avoid the imperative conception of clients and enlarge the reliance of clients.

(4) It is important to bring up the right outlook of life and ethics in general; people to receive the medical care can be unrestricted by making the decisions under the right view of moral.

Acknowledgments This paper was presented at the symposium of the Liaison Committee for Human Genetics, Society Council of Japan (Fukui), 1990.

We wish to thank Dr. J. German, Prof. and Chairman, ret., Department of Human Genetics, University of British Columbia, Canada, for his correction of English expression.

\section{REFERENCES}

Kurjak A, Beazley JM (1985): Fetal therapy: ethical and legal aspects. In: Kurjak A (ed). The fetus as a patient. Elsevier Science Publishers B.V. Amsterdam, London, New York, Tokyo, pp 1-11

Marshall J (1990): The case against experimentation in experiments on embryo. In: Dyson A and Harris J (eds). Experiments on embryos. Routledge, London, New York, pp 55-64

Shinagawa N (1987): Prenatal diagnosis and ethics of fetal therapy. Perinatal Med 17: 1159-1164

Singer P (1990): "Ethics and Fetal Therapy" IIIrd Bioethics Symposium in Kyoto

Steptoe PC, Edwards RG (1978): Birth after reimplantation of a human embryo. Lancet 2: 366

The Warnock Committee (1984): Br Med J 289: 238-239

Vol. 38, No. 3, 1993 